\title{
Academic Performance Motivation: Assessment and Relationship to Mental Health and Academic Achievement
}

\author{
Masayo Uji ${ }^{*}$, Makiko Kawaguchi ${ }^{2}$ \\ ${ }^{1}$ Department of Nursing, Yasuda Women's University, Hiroshima, Japan \\ ${ }^{2}$ Department of Occupational Therapy, Kyushu Chuo Rehabilitation Gakuin, Kumamoto, Japan \\ Email: *ujimasayo@hotmail.co.jp
}

How to cite this paper: Uji, M., \& Kawaguchi, M. (2021). Academic Performance Motivation: Assessment and Relationship to Mental Health and Academic Achievement. Psychology, 12, 374-391. https://doi.org/10.4236/psych.2021.123024

Received: November 20, 2020

Accepted: March 21, 2021

Published: March 24, 2021

Copyright () 2021 by author(s) and Scientific Research Publishing Inc. This work is licensed under the Creative Commons Attribution International License (CC BY 4.0).

http://creativecommons.org/licenses/by/4.0/

\section{(c) (i) Open Access}

\begin{abstract}
The purposes of this study were: 1) to modify the Exercise Motivation Scale (EMS: Fujita, Sato, \& Moriguchi, 2010) which has its theoretical basis on self-determination theory (SDT) in order to adapt it to the academic field; 2) to confirm the factor structure of every subscale of Academic Performance Motivation Scale (APMS) (the revised version of EMS); 3) to evaluate the relationship between the students' motivation styles for academic activities and their psychological well-being; and 4) to examine the relationship between motivation styles and academic achievement level, using data from self-report questionnaire results obtained from 162 college students in Japan. The 26 items in EMS were modified to accommodate to the academic activities, and all of them were adopted in APMS after confirming the content validity. Single-factor structure of all six subscales: Intrinsic Motivation, Integrated Regulation, Identified Regulation, Introjected Regulation, External Regulation, and A-Motivation, was confirmed by CFA. Mental health impairment, academic stress, and perceived social support were applied as indices of psychological well-being. To assess the academic achievement level, the respondents were asked whether they had had to retake at least one examination and/or repeat a year during the last twelve months. Consistent with SDT, the motivation styles with higher levels of autonomy and integration were related to high perceived social support. On the contrary, the motivation styles with lower levels of autonomy and integration were related to poor mental health, increased academic stress, and low perceived social support. It was not concluded whether academic achievement is related to motivation style.
\end{abstract}

\section{Keywords}

Motivation Styles, Self-Determination Theory, 
Academic Performance Motivation Scale, Autonomy, Self-Integration

\section{Introduction}

According to statistics published by Ministry of Education, Culture, Sports, Science and Technology (2019), more than $80 \%$ of senior high school students in Japan proceed to a school of higher education, or level 5 in International Standard Classification of Education (ISCED: UNESCO Institute for Statistics, 2013). Among them, the rate of temporary absence from school and withdrawal are $2.7 \%$ and $2.3 \%$ respectively. Reasons for the absence and withdrawal are reported as academic underachievement, not being able to adjust to school life, transferring to another school, or studying abroad, etc. (Ministry of Education, Culture, Sports, Science and Technology, 2016). Despite the lack of detailed information, it can be assumed that some students would take leave in order to challenge themselves to new fields to achieve self-actualization. On the other hand, some students might have problems related to motivation for academic activities, which can be based on fundamental psycho-social problems, including poor mental health, and/or identity diffusion. These made it necessary for us to examine the relationship of academic motivations to psychological well-being. It is also valuable to see whether some motivation manners contribute to academic underachievement, one of the major reasons for absence and withdrawal as introduced above.

Motivation is generally defined as reasons that underlie behaviors and actions, and in the academic field, reasons that students engage in a variety of school activities (Guay, Chanal, Ratelle, Marsh, Larose, \& Boivin, 2010). Self-determination theory (SDT) focuses on the motivation behind human behavior, emphasizing the importance of distinction between "whether a behavior is autonomous or controlled (Deci, 1996, pp. 2)." According to SDT, the autonomy level influences an individual in a wide range of performances and psychological well-being. The self-integration is the most important pre-requisite for an individual to be autonomous (Deci, 1996).

The motivation style with the highest autonomy and integration is Intrinsic Motivation (Deci \& Ryan, 2000; Ryan \& Deci, 2000). Intrinsic Motivation refers to "the process of doing an activity for its own sake, of doing an activity for the reward that is inherent in the activity itself (Deci, 1996, pp. 21)." It is related to a sense of competence, responsibility, and need for relatedness (Deci, 1996; Deci \& Ryan, 2000) all of which are regarded as the foundation for psychological well-being. In particular, need for a sense of competence and that for relatedness are considered as being innately possessed by human-beings.

Contrary to Intrinsic Motivation, Extrinsic Motivation refers to "the performance of an activity in order to attain some separable outcome (Ryan \& Deci, 2000: p. 71)." It is impossible for human-beings to act/behave only by Intrinsic 
Motivation because they can never be free from social norms and expectations. This means that in many situations, it is inevitable for every human-being to act/behave by Extrinsic Motivation. Thus, it is worth deliberating whether or not an extrinsically motivated act/behavior always impairs human-beings' psychological well-being. According to Deci \& Ryan, even in a case where an individual is extrinsically motivated, his/her act is autonomous when social mores and requests are transformed and integrated into self-endorsed values, leading to psychological well-being. This idea is based on the organismic dialectical metatheory, from which SDT originates. The organismic dialectical metatheory postulates that "humans are active, growth-oriented organisms who are naturally inclined toward integration of their psychic elements into a unified sense of self and integration of themselves into larger social structures (Deci \& Ryan, 2000: p. 229)", and that "internalization is a natural and active process (Deci \& Ryan, 2000: p. 235)" of human-beings. Deci and Ryan do not consider Extrinsic Motivation as distinct from Intrinsic Motivation. Instead, they position Extrinsic Motivation on the continuum from Intrinsic Motivation (Deci \& Ryan, 2000; Ryan \& Deci, 2000). Extrinsic Motivation is classified into four subcategories depending on the autonomy and integration levels and perceived locus of causality. The four subcategories of Extrinsic Motivation are Integrated Regulation, Identified Regulation, Introjected Regulation, and External Regulation, as explained below respectively.

The behaviors derived from Integrated Regulation are accompanied by the highest degree of integration with locus of causality being internal, i.e. self-determined/autonomous. Identified Regulation is defined as the motivation style with the second highest degree of autonomy and integration. An individual with a high level of Identified Regulation accepts the underlying values of their behavior as their own. The subcategory of Extrinsic Motivation styles which comes next to Identified Regulation is Introjected Regulation. An individual whose behavior is based on Introjected Regulation just swallows the underlying values, not fully digests them. Therefore, their locus of causality is external. Among Extrinsic Motivation subcategories, a motivation style with the lowest autonomy and integration levels is External Regulation. An individual with a high level External Regulation behaves in order to attain tangible rewards and/or avoid punishment.

Another type of motivation style other than Intrinsic Motivation and the four subcategories included in Extrinsic Motivation is A-Motivation, which is defined as a "complete lack of self-determination with respect to the target behavior (Deci \& Ryan, 2000: p. 237)."

As such, SDT classifies motivation style into six categories depending on the degrees of autonomy and integration. As explained earlier, autonomy and integration, both necessary for an individual's ego to function soundly, form the basis of his/her psychological well-being. Therefore, we came to the conclusion that a motivation scale which applies SDT would be desirable to apply in this 
study, because one of its purposes was to assess the relationship between motivation styles and other indices related to psychological well-being.

The Exercise Motivation Scale (EMS: Fujita, Sato, \& Moriguchi, 2010) is one of the scales which has its theoretical basis on SDT in assessing motivation styles. It was originally developed as a Japanese version of a questionnaire to assess the students' exercise motivation. It enables us to evaluate all the six motivation styles explained above: Intrinsic Motivation, four types of Extrinsic Motivation, as well as A-Motivation. Its factor structure has already been confirmed as explained below. In this study we decided to modify EMS terms to adopt it to Academic Performance Motivation Scale (APMS) to assess motivation for academic activities, because the decrease in soundness of psychometric properties caused by the modification of the targeted activity was expected to be minimal, and therefore, it was assumed that the APMS would also accurately reflect SDT without major revision.

Fujita et al. (2010) confirmed the six-factor structure of EMS (Intrinsic Motivation, four-subcategories of Extrinsic Motivation, and A-Motivation) with each subscale being single-factor. This was in accordance with SDT. Their study subjects were university and college students in Japan. In a self-completed style questionnaire, the students were asked the reason why they exercise during the exercise class. The number of items in both Intrinsic Motivation and A-Motivation was five, and the number of items in the other four categories: Integrated Regulation, Identified Regulation, Introjected Regulation, and External Regulation was four respectively. The example of Intrinsic Motivation is "I want to experience a feeling of accomplishment when I have completed a physical activity." Integrated Regulation, the first subcategory of Extrinsic Motivation, includes the item "It would be a valuable class to improve my communication skills." Identified Regulation, the second subcategory of Extrinsic Motivation, includes "It is better to gain a minimum level of physical strength." Introjected Regulation, the third subcategory of Extrinsic Motivation, includes "I would be ashamed if I were not able to do something which the other students could." External Regulation, the last subcategory of "Extrinsic Motivation", includes "I will be lonely if I do not do the same activities as the other students." A-Motivation includes "Not sure. I do not find any value in exercising itself." The first aim of this study was to complete APMS by modifying EMS, and then to prove that each APMS subscale has a single factor structure as with the EMS.

We further aimed at investigating relationships between academic motivation styles and psychological well-being. As explained above, motivation styles with high autonomy and integration levels: Intrinsic Motivation and Integrated Regulation, are related to psychological well-being (Deci, 1996). On the other hand, the motivation styles with low autonomy and integration levels: A-Motivation, Extrinsic Regulation, and Introjected Regulation, are related to poor mental health. This idea led us to examine each motivation style assessed by APMS in relation to mental health and in relation to academic stress targeting Japanese 
young adults. Indeed, Baker (2004) demonstrated that amotivated behaviors brought about high levels of perceived stress on university students. Contrarily intrinsically motivated behaviors were related to low levels of perceived stress. Huang, Lv, \& Wu (2016) also proved that intrinsic academic motivation was negatively associated with depression and stress. From these previous studies, we hypothesized that the motivation styles with high levels of autonomy and integration would be related to favorable mental health and low academic stress.

Another important idea included in SDT is that autonomy is concerned with need for relatedness: need to love and to be loved, and need to care and to be cared for (Deci, 1996). Based on the idea that autonomy and independence are not synonymous, Deci (1996) further argues that willing and volitional dependence of an autonomous individual would support his/her psychological well-being. Contrarily, controlled and/or coerced dependence of an individual with a low level of autonomy does not bring about psychological well-being. We can see that Deci does not necessarily negate the low-autonomous individual possessing need for relatedness. The crucial differences between high- and low-autonomous individuals concerning the nature of their relationship with others would be whether or not the relationship is characterized by equality and reciprocity. An individual with highly integrated and autonomous motivation style, such as Intrinsic Motivation and Integrated Regulation, is able to establish equal and reciprocal relationships with others. They do not need to be afraid of being rejected, thus releasing them from conflict associated with seeking help. They can recognize their need for relatedness and can be grateful for getting support. On the other hand, an individual with poorly integrated and autonomous motivation style lacks in "capacity to be alone (Winnicott, 1958: pp. 29-36)", and is afraid of others' evaluation and rejection. As a result, it is safe for them to repress their need for relatedness. However, their repressed need for relatedness, which includes that of being approved and cared for is usually excessive, sometimes even unrealistically bloated, resulting in lack of adequate appreciation even in cases where they succeeded in getting support. Their relation to the other is neither equal nor reciprocal. It was originally premised that the more integrated and autonomous an individual's motivation style, the more he/she is able to get social support and appreciate it favorably, resulting in a higher level of social support he/she reports, i.e. perceived social support.

A contrary causal relationship between perceived social support and motivation style was also presumable: the higher the social support an individual experiences, the more he/she is able to behave and/or act autonomously. Indeed, George, Eys, Oddson, Roy-Charland, Schinke, \& Bruner (2013), targeting a Canadian undergraduate student population, demonstrated results that high social support facilitated students' satisfaction in autonomy and competence, both of which are prerequisites for highly integrated motivation styles such as Intrinsic Motivation or Integrated Regulation, as explained previously. From these, we built a hypothesis that motivations with high levels of autonomy and integration 
are positively related to perceived social support, and motivations with low levels of autonomy and integration are negatively related to perceived social support.

We finally examined whether or not the academic achievement was influenced by academic motivation style. An intervention study conducted by Ryan, \& Grolnick (1986) shows the results that intervention which enhanced Extrinsic Motivation facilitated elementary school students' rote memorization (though short-term retained) but undermined their conceptual understanding. On the other hand, refrainment from the above intervention helped elementary school students' conceptual understanding. Meanwhile, Baker (2004) showed the results that academic achievement level at the university did not differ between Intrinsic Motivation, Extrinsic Motivation, and A-Motivation. Based on these results, we examined whether or not motivation styles are related to academic achievement, more specifically, whether an individual with better academic achievement is more likely to show high levels of Intrinsic Motivation and/or Integrated Regulation, and those with poorer academic achievement are more likely to show high levels of A-Motivation and/or External Regulation. In this study, two external evaluations: experiences of retaking at least one examination and repeating a year, were chosen as indices of the academic achievement.

To summarize, the purposes of this study were: 1 ) to modify the EMS to accommodate to academic activities (the modified scale was named APMS);2) to confirm the single-factor structure of every APMS subscale by CFA; 3 ) to examine the relationships of each motivation style with mental health, academic stress, and perceived social support; and 4) to see whether academic achievement is related to motivation style.

\section{Methods}

\subsection{Procedures}

The protocol of this survey was approved by the institutional review board. The data was obtained from self-report questionnaires conducted twice a year in 2014 and 2015, targeting fourth year college students in Japan. The duration between the first and the second questionnaire survey was five months. Anonymity and voluntary participation were guaranteed. In order to enable us to identify the same participant's questionnaires obtained on two occasions, participants were asked to use the same alias. APMS and Multidimensional Scale of Perceived Social Support (MSPSS: Zimet, Dahlem, Zimet, \& Farley, 1988) were included in the first survey, and Clinical Outcomes in Routine Evaluation-Outcome Measure (CORE-OM: Evans et al., 2000, 2002) was included in the second survey. The questions regarding academic stress, the experience of retaking at least one examination, and that of repeating a year were also included in the second survey.

\subsection{Participants}

Missing data for every APMS item were analyzed proving missing completely at 
random (MCAR). Therefore, pairwise deletion was adopted. One hundred sixty-two college students who completed every item were the target of the analysis. The population included 110 men and 52 women. The subjects ranged from 20 to 42 years of age $(M=23.4, S D=4.4)$.

\subsection{Measurements}

APMS. We changed phrases in EMS (Fujita et al., 2010) to adapt them to academic activities. For example, "I want to experience a feeling of accomplishment when I have completed a physical activity" under EMS Intrinsic Motivation was changed to "I want to experience a feeling of accomplishment when I have acquired academic knowledge", "It is better to gain a minimum level of physical strength" under EMS Identified Regulation was changed to "It is better to gain a minimum level of academic knowledge", etc. As explained in the Introduction, the modified scale was named APMS. Every sentence was carefully examined to confirm that it appropriately assessed the motivation style of each subcategory.

As with EMS, APMS consisted of 26 items. The participants were asked to respond to 26 items regarding their motivations for attending their classes or clinical training with a 5-point Likert scale, from 1 being "the least applicable" to 5 being "the most applicable." As previously noted, the number of items in both Intrinsic Motivation and A-Motivation was five, and the number of items in the other four categories: Integrated Regulation, Identified Regulation, Introjected Regulation, and External Regulation was four respectively.

CORE-OM. The CORE-OM was developed as a standardized brief outcome measure for use in both routine clinical training and psychotherapy research (Evans et al., 2000, 2002). The reliability and validity of the Japanese version of the CORE-OM was confirmed (Uji, Sakamoto, Adachi, \& Kitamura, 2012). It consisted of 34 items, including symptomatic problems (depression, anxiety, physical symptoms, traumatic symptoms), functioning (general functioning, social functioning, close relationship), psychological well-being, and risk to self and others. Each item was rated from 1 (the least applicable) to 5 (the most applicable). Higher scores indicate more serious mental problems.

The Academic Stress Score. This was assessed by an ad hoc item: "Consider your academic stress during this one year, and score its impact on you from 0 (not stressful at all) to 100 (extremely stressful)."

MSPSS. The original version of MSPSS was developed by Zimet et al. (1988). The reliability and validity of the Japanese version of MSPSS was confirmed by Iwasa et al. (2007). Both original and Japanese versions consisted of 12 items, and each item was rated from 1 (the least applicable) to 7 (the most applicable). The higher the total score, the more an individual is aware of social support.

External Evaluation of Academic Performance. As indices of the evaluation on academic performance, experiences of retaking at least one examination and repeating a year were selected. This information was obtained by the students' 
self-report.

\subsection{Statistics}

The internal consistency of each APMS subscale was examined by calculating correlations between an item score and each subscale total score, as well as Cronbach's alpha. CFA was conducted to verify the single-factor structure of each APMS subscale. Gender-specific multi-groups were simultaneously analyzed in order to verify the configural, metric, and scalar invariance. SPSS version 26.0 and Amos version 26.0 were used for CFA. The fit of models with the data was evaluated by the Comparative Fit Index (CFI), the Root Mean Square Error of Approximation (RMSEA), and chi-squared $\left(\chi^{2}\right) / d f$. According to conventional criteria, a good fit would be indicated by CFI $>0.97$, RMSEA $<0.05$, and $\chi^{2} / d f<2$, and an acceptable fit by CFI $>0.95$, and RMSEA $<0.08$, and $\chi^{2} / d f$ $<3$. We also used the Akaike Information Criterion (AIC), in which lower AIC was judged as being preferable.

To assess relationships between motivation styles and psychological well-being, the correlation of each APMS subscale score with the scores of CORE-OM, academic stress, and MSPSS were calculated. The t-test was conducted to examine whether each APMS subscale score significantly differs between two groups: the group with the experience of retaking at least one examination and the group without, as well as the group with the experience of repeating a year and the group without.

\section{Results}

\subsection{Descriptive Statistics}

All items in EMS were modified to adapt to APMS. The items were then all included in the APMS after confirming that they appropriately assessed the motivation style they were categorized under. Every APMS item with descriptive statistics is shown in Table 1. The mean score (SD) of each item as well as each subscale was calculated. Internal consistency was evaluated by correlation between each item and subscale score as well as Chronbach's alpha. The item-total correlation and Chronbach's alpha of each subscale ranged from 0.64 to 0.86 , and from 0.75 to 0.85 respectively, indicating a favorable internal consistency of every subscale.

\subsection{Factor Structure of Each APMS Subscale}

CFA was conducted based on the single-factor model hypothesis for each APMS subscale (Figures 1-6). The fit of the model with the data ranged as follows: from 0.990 to 1.000 for CFI, from 0.000 to 0.078 for RMSEA, and from 0.146 to 1.991 for $\chi^{2} / d f$, all of which indicated either good or acceptable fits (Table 2). The configural, metric, and scalar invariance between genders were also confirmed by simultaneous analysis of multi-groups (Table 3 ). 
Table 1. Mean Score (SD), Correlation between each item score and subscale total score, and Cronbach's alpha of each APMS subscale.

\begin{tabular}{cccc}
\hline Subscale and each item in the subscale & Mean (SD) & $\begin{array}{c}\text { Item-subscale } \\
\text { total correlation }\end{array}$ & $\begin{array}{c}\text { Cronbach's } \\
\text { alpha }\end{array}$ \\
\hline Intrinsic Motivation & $14.2(4.2)$ & & 0.79
\end{tabular}

2. I want to experience a sense of accomplishment when I study hard.

$3.0(1.2) \quad 0.73^{* *}$

8. I feel good when I am absorbed in studying.

$2.7(1.2) \quad 0.75^{\star *}$

14. I am able to feel refreshed when I study.

$2.1(1.0) \quad 0.72^{\star *}$

20. I want to experience a feeling of accomplishment when I have acquired academic knowledge.

$3.4(1.1) \quad 0.75^{\star \star}$

25. I want to pursue pleasures that can only be experienced by studying.

$3.0(1.1) \quad 0.73^{\star *}$

Integrated Regulation

$14.0(3.4)$

0.75

4. I can acquire knowledge which will be useful in the future.

$4.1(0.9) \quad 0.64^{\star *}$

10. It is a valuable class to learn knowledge which is useful for developing my personality.

$3.3(1.2) \quad 0.78^{\star *}$

16. It is a valuable class to improve my communication skills.

$3.6(1.2) \quad 0.84^{* *}$

22. They are valuable classes and clinical training which give me an opportunity to learn about other students.

$3.0(1.2) \quad 0.73^{\star *}$

\begin{tabular}{|c|c|c|c|}
\hline Identified Regulation & $14.4(3.7)$ & & 0.79 \\
\hline $\begin{array}{l}\text { 5. If I do not study, I feel my academic performance } \\
\text { will go down. }\end{array}$ & $3.3(1.2)$ & $0.80^{* *}$ & \\
\hline $\begin{array}{l}\text { 11. It is better to gain a minimum level of academic } \\
\text { knowledge. }\end{array}$ & $3.8(1.1)$ & $0.72^{* *}$ & \\
\hline $\begin{array}{l}\text { 17. I would get into trouble if my academic grades } \\
\text { decline and I have to repeat a year. }\end{array}$ & $3.9(1.3)$ & $0.81^{* *}$ & \\
\hline 23. I want to maintain an acceptable academic record. & $3.3(1.1)$ & $0.78^{* *}$ & \\
\hline Introjected Regulation & $12.1(4.1)$ & & 0.81 \\
\hline $\begin{array}{l}\text { 6. It is shameful if I get a low grade, or I have to } \\
\text { repeat a year. }\end{array}$ & $3.4(1.3)$ & $0.80^{* *}$ & \\
\hline $\begin{array}{l}\text { 12. I do not want to cause trouble for other students } \\
\text { due to my failure in clinical training and/or in } \\
\text { examinations. }\end{array}$ & $2.8(1.3)$ & $.73^{\star *}$ & \\
\hline $\begin{array}{l}\text { 18. I would be ashamed if I were not able to do } \\
\text { something which the other students could. }\end{array}$ & $3.3(1.3)$ & $0.84^{\star *}$ & \\
\hline $\begin{array}{l}\text { 24. I do not want other students to see me getting } \\
\text { poor grades. }\end{array}$ & $2.6(1.2)$ & $0.82^{\star *}$ & \\
\hline
\end{tabular}
poor grades. 


\section{Continued}

External Regulation

1. If I do not study, I feel I do not belong.

7. I will be lonely if I do not do the same activities as the other students.

13. I would feel awkward if I did not do the same activities as the other students.

19. I would feel out of place in the classroom if I did not do the same activities as the other students.
$8.9(3.9)$

0.85
A-Motivation

3. Not sure. I do not find any value in studying itself.

9. Not sure. I do not think that my grades will

improve even if I study.

15. Not sure. I think it is a waste of time to study.

21. Not sure. Even if I set my goal, I do not think

I can accomplish it.

26. Not sure. I do not think I am suitable for studying.

${ }^{* *} p<0.01$
$2.2(1.2) \quad 0.86^{* *}$

$2.3(1.3) \quad 0.86^{\star *}$

$2.2(1.1) \quad 0.82^{\star *}$

$2.2(1.2) \quad 0.77^{\star *}$

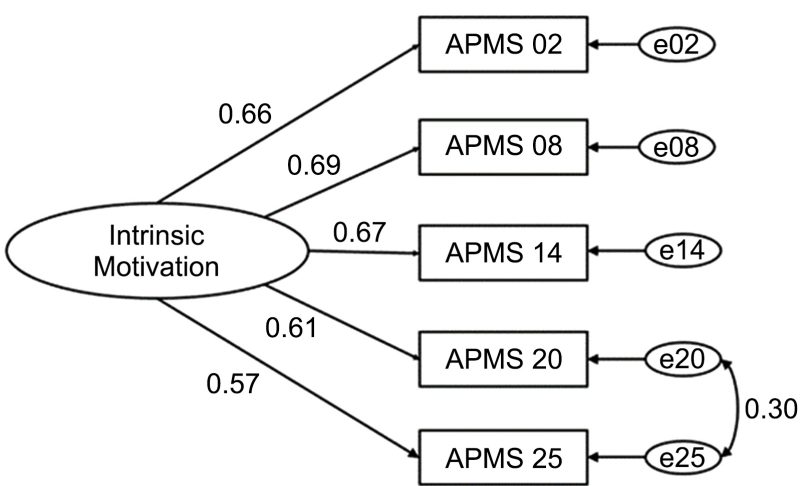

Figure 1. Confirmatory factor analysis of intrinsic motivation subscale of APMS. The numerical values indicate standardized coefficients.

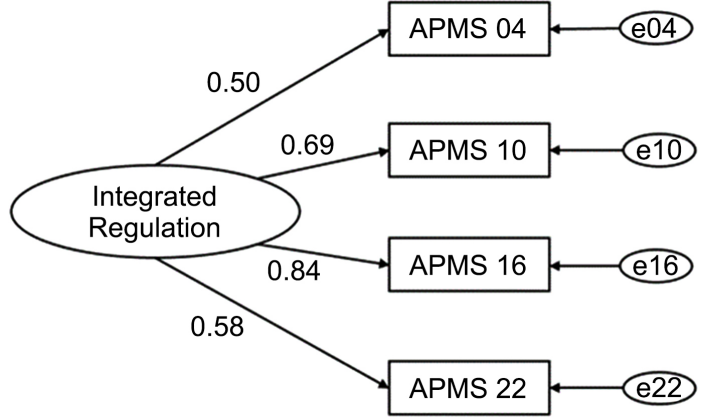

Figure 2. Confirmatory factor analysis of integrated regulation subscale of APMS. The numerical values indicate standardized coefficients. 


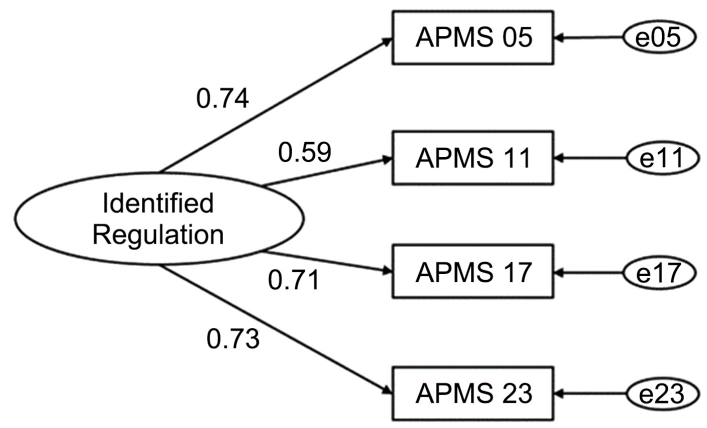

Figure 3. Confirmatory factor analysis of identified regulation subscale of APMS. The numerical values indicate standardized coefficients.

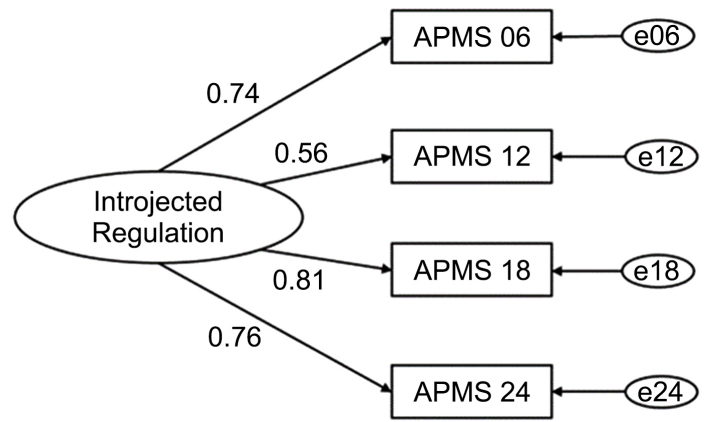

Figure 4. Confirmatory factor analysis of introjected regulation subscale of APMS. The numerical values indicate standardized coefficients.

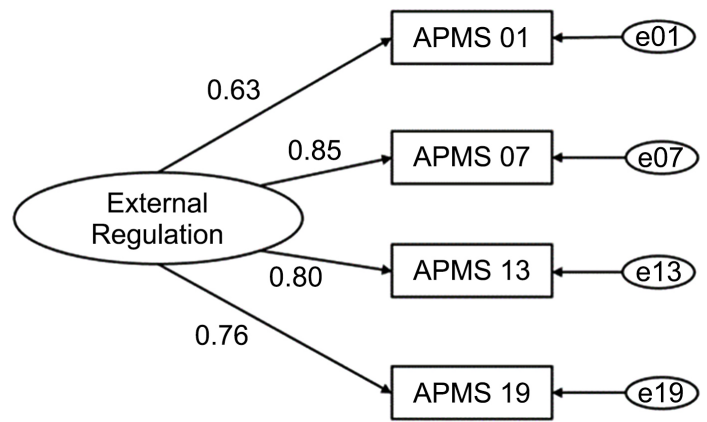

Figure 5. Confirmatory factor analysis of external regulation subscale of APMS. The numerical values indicate standardized coefficients.

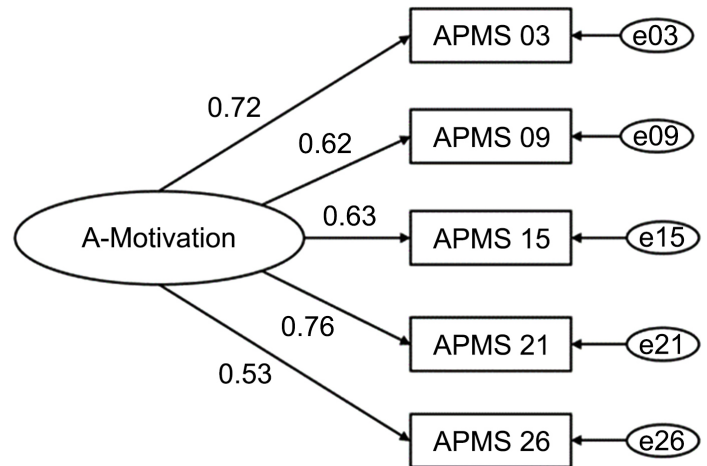

Figure 6. Confirmatory factor analysis of a-motivation subscale of APMS. The numerical values indicate standardized coefficients. 
Table 2. Fitness of each APMS subscale single-factor structure.

\begin{tabular}{cccccc}
\hline Motivation Category & Motivation Subcategory & CFI & RMSEA & $\chi^{2} / d f$ & AIC \\
\hline Intrinsic Motivation & & 1.000 & 0.000 & 0.805 & 35.2 \\
\hline \multirow{3}{*}{ Extrinsic Motivation } & Integrated Regulation & 1.000 & 0.000 & 0.146 & 24.3 \\
& Identified Regulation & 0.990 & 0.075 & 1.904 & 27.8 \\
& Introjected Regulation & 0.995 & 0.056 & 1.509 & 27.0 \\
& External Regulation & 0.993 & 0.078 & 1.991 & 28.0 \\
\hline \multirow{2}{*}{ A-Motivation } & & 1.000 & 0.000 & 0.675 & 33.4 \\
\hline
\end{tabular}

Table 3. Configural, metric, and measurement invariance: Male $(n=110)$ vs. Female $(n=$ 52 ).

\begin{tabular}{|c|c|c|c|c|}
\hline \multicolumn{5}{|c|}{ Intrinsic Motivation } \\
\hline & CFI & RMSEA & $\chi^{2} / \mathrm{df}$ & $\mathrm{AIC}$ \\
\hline Configural & 1.000 & 0.000 & 0.841 & 70.7 \\
\hline Metric & 1.000 & 0.000 & 0.768 & 65.2 \\
\hline Scalar & 0.979 & 0.039 & 1.247 & 67.2 \\
\hline \multicolumn{5}{|c|}{ Integrated Regulation } \\
\hline & CFI & RMSEA & $\chi^{2} / \mathrm{df}$ & AIC \\
\hline Configural & 1.000 & 0.000 & 0.932 & 51.7 \\
\hline Metric & 1.000 & 0.014 & 1.030 & 49.2 \\
\hline Scalar & 1.000 & 0.000 & 0.932 & 51.7 \\
\hline \multicolumn{5}{|c|}{ Identified Regulation } \\
\hline & CFI & RMSEA & $\chi^{2} / \mathrm{df}$ & AIC \\
\hline Configural & 0.990 & 0.051 & 1.417 & 53.7 \\
\hline Metric & 0.985 & 0.048 & 1.373 & 51.6 \\
\hline Scalar & 0.990 & 0.051 & 1.417 & 56.0 \\
\hline \multicolumn{5}{|c|}{ Introjected Regulation } \\
\hline & $\mathrm{CFI}$ & RMSEA & $\chi^{2} / \mathrm{df}$ & AIC \\
\hline Configural & 1.000 & 0.000 & 0.120 & 55.2 \\
\hline Metric & 1.000 & 0.000 & 0.542 & 48.7 \\
\hline Scalar & 1.000 & 0.000 & 0.120 & 52.2 \\
\hline \multicolumn{5}{|c|}{ External Regulation } \\
\hline & CFI & RMSEA & $x^{2} / \mathrm{df}$ & $\mathrm{AIC}$ \\
\hline Configural & 1.000 & 0.000 & 0.906 & 53.8 \\
\hline Metric & 0.985 & 0.072 & 1.825 & 55.1 \\
\hline Scalar & 0.983 & 0.057 & 1.517 & 51.7 \\
\hline \multicolumn{5}{|c|}{ A-Motivation } \\
\hline & CFI & RMSEA & $\chi^{2} / \mathrm{df}$ & $\mathrm{AIC}$ \\
\hline Configural & 1.000 & 0.000 & 0.971 & 69.7 \\
\hline Metric & 1.000 & 0.000 & 0.887 & 64.4 \\
\hline Scalar & 1.000 & 0.005 & 1.004 & 61.1 \\
\hline
\end{tabular}




\subsection{The Relationship between Each APMS Subscale Score and CORE-OM Score}

A-Motivation and External Regulation positively correlated with the CORE-OM score ( $r=0.30, p<0.01, r=0.20, p<0.05$, respectively), which meant that these motivation styles-(i.e., with the lowest and second lowest levels of autonomy and integration)-were related to poor mental health (Table 4). The other motivation style scores did not have significant correlations with CORE-OM score.

\subsection{The Relationship between Each APMS Subscale Score and Academic Stress Score}

External Regulation and Introjected Regulation-motivation styles with the lowest and second lowest levels of autonomy and integration among the Extrinsic Motivation-positively correlated with academic stress score $(r=0.19, p<$ $0.05, r=0.18, p<0.05$, respectively) (Table 4 ). The other motivation style scores did not correlate with academic stress score.

\subsection{The Relationship between Each APMS Subscale Score and MSPSS Score}

Intrinsic Motivation and Integrated Regulation-motivation styles with the highest and second highest levels of autonomy and integration-positively correlated with the MSPSS score $(r=0.29, p<0.01, r=0.44, p<0.01$, respectively). On the other hand, A-Motivation-the motivation style with the lowest levels of autonomy and integration-correlated negatively with the MSPSS score ( $r=$ $-0.27, p<0.01$ ) (Table 4). These results meant that the higher the levels of autonomy and integration in an individual student's motivation style, the more he/she is aware of social support.

\subsection{APMS Subscale Score Differences between the Group Retaking at Least One Examination and the Group Not Retaking an Examination}

No statistically significant differences were identified regarding all the APMS subscale scores between the two groups (Table 5). This meant that motivation style was not related to whether or not an individual student retook at least one examination.

Table 4. Correlation of each APMS subscale score with the scores of CORE-OM, academic stress, and MSPSS.

\begin{tabular}{ccccccc}
\hline & Intrinsic & \multicolumn{5}{c}{ Extrinsic Motivation } \\
\cline { 3 - 6 } & Motivation & $\begin{array}{c}\text { Integrated } \\
\text { Regulation }\end{array}$ & $\begin{array}{c}\text { Identified } \\
\text { Regulation }\end{array}$ & $\begin{array}{c}\text { Introjected } \\
\text { Regulation }\end{array}$ & $\begin{array}{c}\text { External } \\
\text { Regulation }\end{array}$ & A-Motivation \\
\hline CORE-OM & 0.07 & -0.01 & 0.08 & 0.11 & $0.20^{*}$ & $0.30^{* *}$ \\
Academic Stress & -0.12 & -0.11 & 0.01 & $0.18^{*}$ & $0.19^{*}$ & 0.14 \\
MSPSS & $0.29^{* *}$ & $0.44^{* *}$ & 0.02 & 0.01 & -0.04 & $-0.27^{* *}$ \\
\hline${ }^{*} p<0.05 ;{ }^{* *} p<0.01$. & & & & &
\end{tabular}


Table 5. Comparison of each APMS subscale score between students with experience of retaking at least one examination and those without, and students with repeating a year and those without (t-test).

\begin{tabular}{|c|c|c|c|c|c|c|}
\hline & \multicolumn{3}{|c|}{ Retook at least one examination } & \multicolumn{3}{|c|}{ Repeated a year } \\
\hline & $\begin{array}{c}\text { Yes } \\
(n=56)\end{array}$ & $\begin{array}{c}\text { No } \\
(n=104)\end{array}$ & \multirow{2}{*}{$t$ value } & $\begin{array}{c}\text { Yes } \\
(n=7)\end{array}$ & $\begin{array}{c}\text { No } \\
(n=153)\end{array}$ & \multirow{2}{*}{$t$ value } \\
\hline & \multicolumn{2}{|c|}{ Mean score $(S D)$} & & \multicolumn{2}{|c|}{ Mean score $(S D)$} & \\
\hline $\begin{array}{c}\text { Intrinsic } \\
\text { Motivation }\end{array}$ & $14.0(3.7)$ & $14.4(4.3)$ & -0.60 & $14.9(4.8)$ & $14.2(4.1)$ & 0.40 \\
\hline $\begin{array}{l}\text { Integrated } \\
\text { Regulation }\end{array}$ & $13.9(3.2)$ & $14.2(3.5)$ & -0.57 & $14.1(3.6)$ & $14.0(3.3)$ & 0.05 \\
\hline $\begin{array}{l}\text { Identified } \\
\text { Regulation }\end{array}$ & $13.7(3.8)$ & $14.8(3.5)$ & -1.90 & $11.0(4.0)$ & $14.8(3.6)$ & $-2.58^{*}$ \\
\hline $\begin{array}{l}\text { Introjected } \\
\text { Regulation }\end{array}$ & $11.7(4.1)$ & $12.3(4.2)$ & -0.91 & $10.3(3.7)$ & $12.2(4.1)$ & -1.20 \\
\hline $\begin{array}{c}\text { External } \\
\text { Regulation }\end{array}$ & $9.1(3.6)$ & $8.8(4.1)$ & 0.41 & $10.0(4.0)$ & $8.9(3.9)$ & 0.74 \\
\hline A-Motivation & $11.0(3.7)$ & $10.3(3.8)$ & 1.02 & $15.4(1.9)$ & $10.3(3.6)$ & $3.70^{\star *}$ \\
\hline
\end{tabular}

\subsection{APMS Subscale Score Differences between the Group Repeating a Year and the Group Not Repeating a Year}

The group repeating a year showed a significantly higher score in A-Motivation subscale $(t=3.70, p<0.01)$ and a significantly lower score in Identified Regulation subscale $(t=-2.58, p<0.05)$ (Table 5).

\section{Discussion}

In this study, we modified EMS phrases to adapt them to academic activities, and verified that each APMS subscale has single-factor structure regardless of the respondent's gender. This meant that APMS, like the EMS, is appropriate for assessing each of the six motivation styles in SDT. Furthermore, of particular interest was the relationship between the subscale scores of APMS and other scores: CORE-OM, academic stress score, and MSPSS, as well as the academic achievement represented by retaking at least one examination and/or repeating a year, which will be discussed in detail below.

Two motivation styles with low levels of autonomy and integration, A- Motivation and External Regulation, had a significant correlation with CORE-OM with a positive value, which meant that these motivation styles were related to poor mental health. As noted previously, CORE-OM enables us to evaluate not only mental symptoms of subjects, but also their social functioning, close relationships, and psychological well-being. Furthermore, of particular importance is that A-Motivation showed a significant correlation with perceived social support with a negative value, as discussed later. These results would suggest that an 
individual who acts and behaves with low levels of autonomy and integration has difficulties in acquiring social resources which enable them to live as a social-being.

Regarding the relationship between each motivation style and academic stress, External Regulation, the lowest levels of autonomy and integration among Extrinsic Motivation, positively correlated with the academic stress score. Also, Introjected Regulation, the second lowest levels of autonomy and integration among Extrinsic Motivation, correlated positively with the academic stress score. These findings can be interpreted as follows: if the social requirements and expectations are not integrated into one's own values, an individual is more likely to feel stress due to a feeling of being controlled by external expectations, resulting in poor mental health.

Although two motivation styles with high levels of autonomy and integration: Intrinsic Motivation and Integrated Regulation, did not have significant correlations with CORE-OM and academic stress score, they positively correlated with perceived social support. This was consistent with our hypotheses, meaning that an individual with highly autonomous and integrated motivation style is able to either get others' support and/or evaluate it adequately, or both. An Alternative interpretation would be that a student who is aware of strong social support is able to behave more autonomously. Meanwhile, A-Motivation negatively correlated with perceived social support, suggesting that an individual with A- Motivation style either is unable to get social support or is unable to appreciate it even if he/she succeeded in receiving it, or both. It is also possible that a student who lacks in social support is more likely to become amotivated. Poorly integrated and autonomous motivation styles among Extrinsic Motivation, such as External Regulation and Introjected Regulation did not have significant correlation with perceived social support. This suggests that those with A-Motivation style have more severe conflicts than those with External Regulation and Introjected Regulation when relating to others, which make it difficult for them to seek help when necessary.

The results next to be discussed are the relationship between the motivation styles and evaluation of academic achievement. There was no significant difference between the students who retook at least one examination and those who did not. On the other hand, compared to the students who repeated a year, those who did not repeat a year marked a significantly higher score regarding Identified Regulation, which is defined as a motivation style with relatively higher levels of autonomy and integration among Extrinsic Motivation. In addition, the students who repeated a year were more likely to mark a higher A-Motivation score than those who did not. It is probable that A-Motivation contributes to increasing the risk of repeating a year, and Identified Regulation has an effect in decreasing the risk thereof. However, the scores of the other four motivation styles: Intrinsic Motivation, Integrated Regulation, Introjected Regulation, and External Regulation, did not differ between the two groups. We cannot conclude 
whether or not the levels of autonomy and integration impact academic evaluation by school teachers, because in this study only rough information-retaking at least one examination and/or repeating a year-was applied as criteria of academic achievement evaluation. As we can see from the previous research briefly referred in the Introduction, it seems that whether or not the academic achievement is influenced by academic motivation styles depends on indices applied for academic achievement evaluation. If more detailed information on each student's academic evaluation (i.e., examination scores and/or teachers' qualitative evaluation on deep learning such as conceptual understanding as with the study conducted by Ryan \& Grolnick (1986), reconstruction of existing ideas, and creation of new concepts) had been applied, an individual with high Intrinsic Motivation and/or Integrated Regulation levels would have demonstrated a high level of academic achievement and an individual with high External Regulation and/or Introjected Regulation levels would have demonstrated undermined academic achievement. However, of particular importance is that the paramount benefit of highly autonomous and integrated motivation does not exist in external evaluation, but in an individual's internal experiences. It can be assumed that highly intrinsically motivated students' attitudes for studying are reflected in their anticipation for new knowledge as well as voluntary sharing of the pleasure of learning with others, including school teachers. Even so, it is worth noting that the index to detect serious underachievers (those who repeat a year) was proven to be related to A-Motivation, in other words, the lack of motivation.

Finally, the limitations of this study should be mentioned. The first is that the sample size was relatively small. In particular, the number of the students who repeated a year was seven, which was extremely small compared to the number who did not. Therefore, the comparisons between the two groups obtained by $\mathrm{t}$-test is remains unconvincing. The second is that due to the anonymous participation, we were not able to obtain the students' detailed academic achievement evaluation carried out by the teachers. We were only able to ask the students whether they retook at least one examination and/or repeated a year. However, despite the lack of detailed information regarding their academic achievement, the finding that A-Motivation contributed to increasing the experience of repeating a year is worthy of notice.

To summarize, the results of this study suggest that regardless of whether motivation styles impact academic achievement, motivation styles with high levels of autonomy and integration were related to high perceived social support. Contrarily, those with low autonomy and integration were related to poor mental health, high academic stress, and low perceived social support. Assuming that there is a mutually facilitating relationship between psychological well-being-represented by favorable mental health, low academic stress, and high perceived social support - and levels of autonomy and integration in each student's academic motivation style, the following two points can be proposed as implications for an educational setting: 1) for students' psychological well-being, they 
should be provided with a learning environment that facilitates their autonomy and internal volition; and 2) for students with low autonomy and integration levels in their academic motivation, interventions to improve their psychological well-being would be effective.

\section{Acknowledgements}

The authors would like to thank all the participants in the present study.

\section{Conflicts of Interest}

The authors declare no conflicts of interest regarding the publication of this paper.

\section{References}

Baker, S. R. (2004). Intrinsic, Extrinsic, and Amotivational Orientations: Their Role in University Adjustment, Stress, Well-Being, and Subsequent Academic Performance. Current Psychology, 23, 189-202. https://doi.org/10.1007/s12144-004-1019-9

Deci, E. L. (1996). Why We Do What We Do. Understanding Self-Motivation. New York: Penguin Books.

Deci, E. L., \& Ryan, R. M. (2000). The "What" and "Why" of Goal Pursuits: Human Needs and the Self-Determination of Behavior. Psychological Inquiry, 11, 227-268. https://doi.org/10.1207/S15327965PLI1104_01

Evans, C., Connell, J., Barkham, M., Margison, F., McGrath, G., Mellor-Clark, J., \& Audin, K. (2002). Towards a Standardized Brief Outcome Measure: Psychometric Properties and Utility of the CORE-OM (Clinical Outcomes in Routine Evaluation-Outcome Measure). British Journal of Psychiatry, 180, 51-60.

https://doi.org/10.1192/bjp.180.1.51

Evans, C., Mellor-Clark, J., Margison, F., Barkham, M., Audin, K., Connell, J., \& McGrath, G. (2000). CORE: Clinical Outcomes in Routine Evaluation. Journal of Mental Health, 9, 247-255. https://doi.org/10.1080/713680250

Fujita, T., Sato, Y., \& Moriguchi, T. (2010). A Study of Exercise Motivation Based on Self-Determination Theory. Bulletin of the Faculty of Education, Kagoshima University. Cultural and Social Science, 61, 61-71. (In Japanese)

George, M., Eys, M. A., Oddson, B., Roy-Charland, A., Schinke, R. J., \& Bruner, M. W. (2013). The Role of Self-Determination in the Relationship between Social Support and Physical Activity Intentions. Journal of Applied Social Psychology, 43, 1333-1341. https://doi.org/10.1111/jasp.12142

Guay, F., Chanal, J., Ratelle C. F., Marsh, H. W., Larose, S., \& Boivin, M. (2010). Intrinsic, Identified, and Controlled Types of Motivation for School Subjects in Young Elementary School Children. British Journal of Educational Psychology, 80, 711-735. https://doi.org/10.1348/000709910X499084

Huang, H., Lv, W., \& Wu, J. (2016). Relationship between Intrinsic Motivation and Undergraduate Students' Depression and Stress: The Moderating Effect of Interpersonal Conflict. Psychological Reports, 119, 527-538. https://doi.org/10.1177/0033294116661512

Iwasa, H., Gondo, Y., Masui, Y., Inagaki, H., Kawaai, C., Otsuka, R., Suzuki, T. et al. (2007). Reliability and Validity of the Japanese Version of the Multidimensional Scale of Perceived Social Support among Middle-Aged and Elderly People Living in a Japa- 
nese Community. Journal of Health and Welfare Statistics, 54, 26-33. (In Japanese)

Ministry of Education, Culture, Sports, Science and Technology (2019). Report on School Basic Survey in 2019. (In Japanese) https://www.mext.go.jp/content/20191220-mxt_chousa01-000003400_1.pdf

Ministry of Education, Culture, Sports, Science and Technology (2016). Report on Student Withdraw Dropout and Leave of Absence. (In Japanese) https://www.mext.go.jp/b_menu/houdou/26/10/_icsFiles/afieldfile/2014/10/08/135242 5_01.pdf

Ryan, R. M., \& Deci, E. L. (2000). Self-Determination Theory and the Facilitation of Intrinsic Motivation, Social Development, and Well-Being. American Psychologist, 55, 68-78. https://doi.org/10.1037/0003-066X.55.1.68

Ryan, R. M., \& Grolnick, W. (1986). Origins and Pawns in the Classroom: Self-Report and Projective Assessment of Individual Differences in Children's Perceptions. Journal of Personality and Social Psychology, 50, 550-558. https://doi.org/10.1037/0022-3514.50.3.550

Uji, M., Sakamoto, A., Adachi, K., \& Kitamura, T. (2012). Psychometric Properties of the Japanese Version of the Clinical Outcomes in Routine Evaluation-Outcome Measure. Comprehensive Psychiatry, 53, 600-608.

https://doi.org/10.1016/j.comppsych.2011.09.006

UNESCO Institute for Statistics (2013). International Standard Classification of Education. Fields of Education and Training 2013 (ISCED-F 2013) Detailed Field Descriptions.

Winnicott, D. W. (1958). The Maturational Processes and the Facilitating Environment. London: Karnac Books.

Zimet, G. D., Dahlem, N. W., Zimet, S. G., \& Farley, G. K. (1988). The Multidimensional Scale of Perceived Social Support. Journal of Personality Assessment, 52, 30-41. https://doi.org/10.1207/s15327752jpa5201_2 